\title{
Sistemas personalizados de dosificación: el camino hacia la seguridad y efectividad de la medicación
}

\author{
Ma Jesús Rodríguez Arcas', Marina Cánovas Mata', Virginia López Fernández² \\ 1. Farmacéutica comunitaria en Cartagena (Región de Murcia). 2. Técnica en Farmacia en Cartagena (Región de Murcia).
}

\section{PALABRAS CLAVE}

Reacciones adversas, adherencia, seguridad, efectividad, atención farmacéutica, farmacia

comunitaria

\section{ABREVIATURAS}

COF: Colegio Oficial de Farmacéuticos GGT: gamma glutamil transferasa PRM: problema relacionado con la medicación

RNM: resultado negativo asociado a la medicación SPD: sistemas personalizados de dosificación

ZAP: zona de atención personalizada

\section{KEYWORDS}

Adverse drug reaction, adherence, safety, effectiveness, pharmaceutical care, community pharmacy, SPD
Recibido: 23/12/2019

Aceptado: 15/4/2020

Disponible online: 11/5/2020

\section{Presentación del caso}

La cuidadora del paciente acude a la farmacia a retirar la medicación mensual e indica al técnico en el mostrador que necesita ayuda porque su marido toma mucha medicación y ella no es capaz de organizársela adecuadamente.

Desde el mostrador se le deriva a la zona ZAP de la farmacia donde el farmacéutico le informa del servicio de sistema personalizado de dosificación (SPD) que ofrece la farmacia, explicándole que le podemos preparar la medicación semanalmente en blíster personalizados, comprobando la efectividad y seguridad del tratamiento farmacológico.

La cuidadora lo consulta con el paciente y al día siguiente viene a la farmacia donde nos firma el consentimiento informado para participar en el programa y comenzamos a recoger todos sus datos de salud y de medicación.

La farmacéutica se encuentra capacitada para realizar el servicio de SPD según la metodología consensuada entre Colegio Oficial de Farmacéuticos (COF) de la Región de Murcia y el Servicio Murciano de Salud.

Los datos de la medicación del paciente los extraemos de la receta electrónica preguntando uno a uno el problema de salud para el que ha sido prescrita, fecha de inicio y contrastando la dosis prescrita con la que realmente toma, para detectar problemas en la adherencia.

Junto a la receta electrónica le hemos solicitado los datos analíticos más recientes del paciente.

El paciente fue operado hace 2 años de un teratoma mediastinal pulmonar y a partir de ese momento se queja de un dolor en el tórax que le impide salir a la calle y está en tratamiento en la Unidad del Dolor.

En cuanto a la adherencia a los tratamientos la cuidadora no es capaz de decirnos las dosis correctas de los fármacos y además nos indica que a veces deja de tomarlos cuando piensa que no le sientan bien; aunque de eso no informa al médico.

En su analítica más reciente de hace 4 meses observamos que presenta descontrolada la glucosa $113 \mathrm{mg} / \mathrm{dl}$ (hemoglobina glicosilada 6,4 \%, un filtrado glomerular de $84,34 \mathrm{ml} / \mathrm{min} / 1,73 \mathrm{~m}^{2}$ (correspondiente a un estadio 2) y la GGT $129 \mathrm{U} / \mathrm{L}$ (v. referencia: 10-71); colesterol total $197 \mathrm{mg} / \mathrm{dl}$ y triglicéridos: $225 \mathrm{mg} / \mathrm{dl}$.

Todas las dosis están dentro del intervalo adecuado descrito en la bibliografía.

Desde hace unos meses le aparecen crisis de ansiedad que controla con lorazepam a demanda.

Los datos del paciente para su evaluación a fecha de inicio del servicio de SPD se muestran en la tabla 1, donde se recoge el estado de situación del paciente. Esta hoja permite relacionar en el tiempo los problemas de salud con los tratamientos farmacológicos del paciente; incluyendo las enzimas metabólicas y proteinas transportadoras de los tratamientos. 


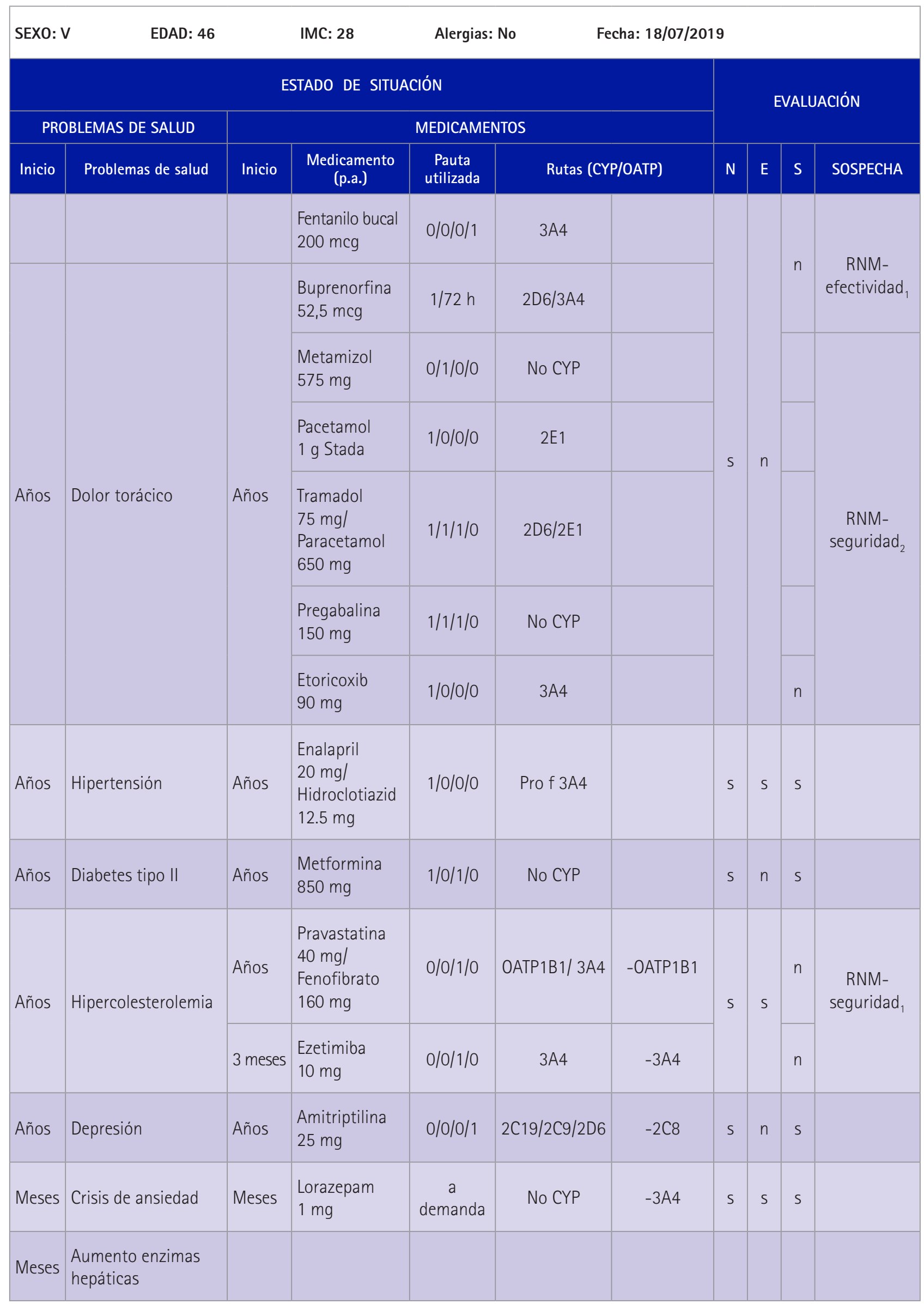




\section{Estudio y evaluación}

$\mathrm{Al}$ estudiar la efectividad y seguridad de su medicación encontramos diversos problemas relacionados con la medicación (PRM) (1) que se analizan a continuación.

\section{Sindrome serotoninérgico}

Tramadol, fentanilo y amitriptilina pueden provocar un síndrome serotoninérgico (2). Como el paciente no presenta síntomas no intervenimos, pero lo dejamos monitorizado para estar alerta ante la aparición de cualquier sintoma.

\section{Fentanilo y buprenorfina}

Fentanilo y buprenorfina no deben prescribirse de manera concomitante, ya que uno actúa como agonista/antagonista y el otro como parcialmente agonista; por lo que se produce una disminución del efecto analgésico de fentanilo. RNM efectividad no cuantitativa . $^{2}$

Esto podría dar lugar a la aparición de crisis de ansiedad por el síndrome de abstinencia. RNM seguridad cuantitativa ${ }_{2}$.

A nivel renal, fentanilo produce la liberación de hormona antidiurética (3) y etoricoxib puede provocar daño renal (4). Debido a que el paciente ya presenta un estadio 2 del filtrado glomerular, lo dejamos monitorizado por si aparecen efectos adversos derivados de este tratamiento.

Fenofibrato, pravastatina y ezetimiba pueden provocar como efectos secundarios rabdomiolisis (empeorando el cuadro clínico de dolor que refiere el enfermo) y daño hepático, provocando un aumento de la GGT $(2,5)$. RNM seguridad no cuantitativa.

Pravastatina inhibe el transportador orgánico OATP1B1 (6), por lo que fenofibrato puede ver elevada su concentración sanguínea; y ezetimiba se puede comportar como un inhibidor débil del CYP3A4, lo que daría lugar a un aumento en la concentración sérica de fenofibrato por inhibición de su metabolismo (7). Debido a este aumento en la concentración de fenofibrato, puede verse incrementado el riesgo de sufrir las reacciones adversas descritas anteriormente.

\section{Intervención}

Al comprobar que el paciente presenta elevada la concentración de GGT y que puede estar producido por el uso concomitante de la estatina y el fibrato, se escribe al médico un informe a través del paciente, en el que se especifica el riesgo del aumento de los valores de enzimas hepáticas, especialmente de la GGT.

En el mismo informe se indica que la terapia analgésica podría no ser la adecuada, debido a la posible disminución del efecto del fentanilo por el uso concomitante de buprenorfina, que puede dar lugar a la aparición de síntomas de abstinencia, como las crisis de ansiedad que padece, para lo que toma lorazepam a demanda.

\section{Resultados}

El paciente solicitó cita con su médico de atención primaria, pero al estar de vacaciones no le dieron cita hasta tres semanas más tarde; por lo que se le recomendó suspender Pravafenix en espera de consulta con el médico.

El médico confirmó la suspensión del tratamiento con pravastatina $\mathrm{y}$ fenofibrato, y solicitó una analítica para comprobar el estado de la función hepática y los niveles de colesterol y triglicéridos. En esta analítica el colesterol y triglicéridos seguían dentro de los rangos adecuados y los valores de GGT disminuyeron a valores de $71 \mathrm{U} / \mathrm{L}$, dentro del intervalo adecuado.

Actualmente el paciente retira la medicación semanalmente y segui- mos monitorizándolo para prevenir la aparición de las reacciones adversas descritas anteriormente.

\section{Conclusiones}

El SPD, asociado a una revisión de la medicación, se presenta como una herramienta indiscutible en la mejora de la adherencia por parte del paciente. Esta adherencia no sólo se ve mejorada por el emblistado de la medicación del paciente, sino de manera indirecta, debido a la mejora en la efectividad y seguridad de los pacientes.

\section{Referencias bibliográficas}

1. Foro de Atención FarmacéuticaFarmacia Comunitaria (Foro AF-FC). Guía práctica para los Servicios Profesionales Farmacéuticos Asistenciales en la Farmacia Comunitaria. Madrid: Consejo General de Colegios Oficiales de Farmacéuticos; 2019.

2. Base de Datos de medicamentos del Consejo General de Farmacéuticos (Bot PLUS 2.0): https://botplusweb. portalfarma.com

3. Kokko H, Hall PD, Afrin LB. Fentanyl-associated syndrome of inappropriate antidiuretic hormone secretion. Pharmacotherapy. 2002;22(9):1188-92. doi:10.1592/phco.22.13.1188.33526

4. Tripathy S, Dash SC. Etoricoxib-induced life-threatening hyperkalemia and acute kidney dysfunction against the background of telmisartan and a low sodium diet. Int J Emerg Med. 2010; 20;3(4):443-6. doi:10.1007/ s12245-010- 0208-6

5. Yan $\mathrm{MM}, \mathrm{Wu} \mathrm{SS}$, Ying $\mathrm{YQ}, \mathrm{Lu} \mathrm{N}$, Zhong MK. Safety assessment of concurrent statin treatment and evaluation of drug interactions in China. SAGE Open Med. 2018;6:1-9. doi:10.1177/2050312118798278

6. Karlgren M, Vildhede A, Norinder U, Wisniewski JR, Kimoto E, Lai Y, Haglund U, Artursson P. Classification of inhibitors of hepatic organic anion transporting polypeptides (OATPs): influence of protein expression on drug-drug interactions. J Med Chem. 2012;55(10):4740-63.

7. Drugbank: http://www.drugbank.ca/ [Accessed: September 19] 